Document downloaded from:

http://hdl.handle.net/10251/103223

This paper must be cited as:

Salvador Zuriaga, P.; Martínez Fernández, P.; Villalba Sanchis, I.; Insa Franco, R. (2017). Modelling energy consumption in diesel multiple units. Proceedings of the Institution of Mechanical Engineers. Part F, Journal of rail and rapid transit (Online). 232(5):1-10. doi:10.1177/0954409717737226

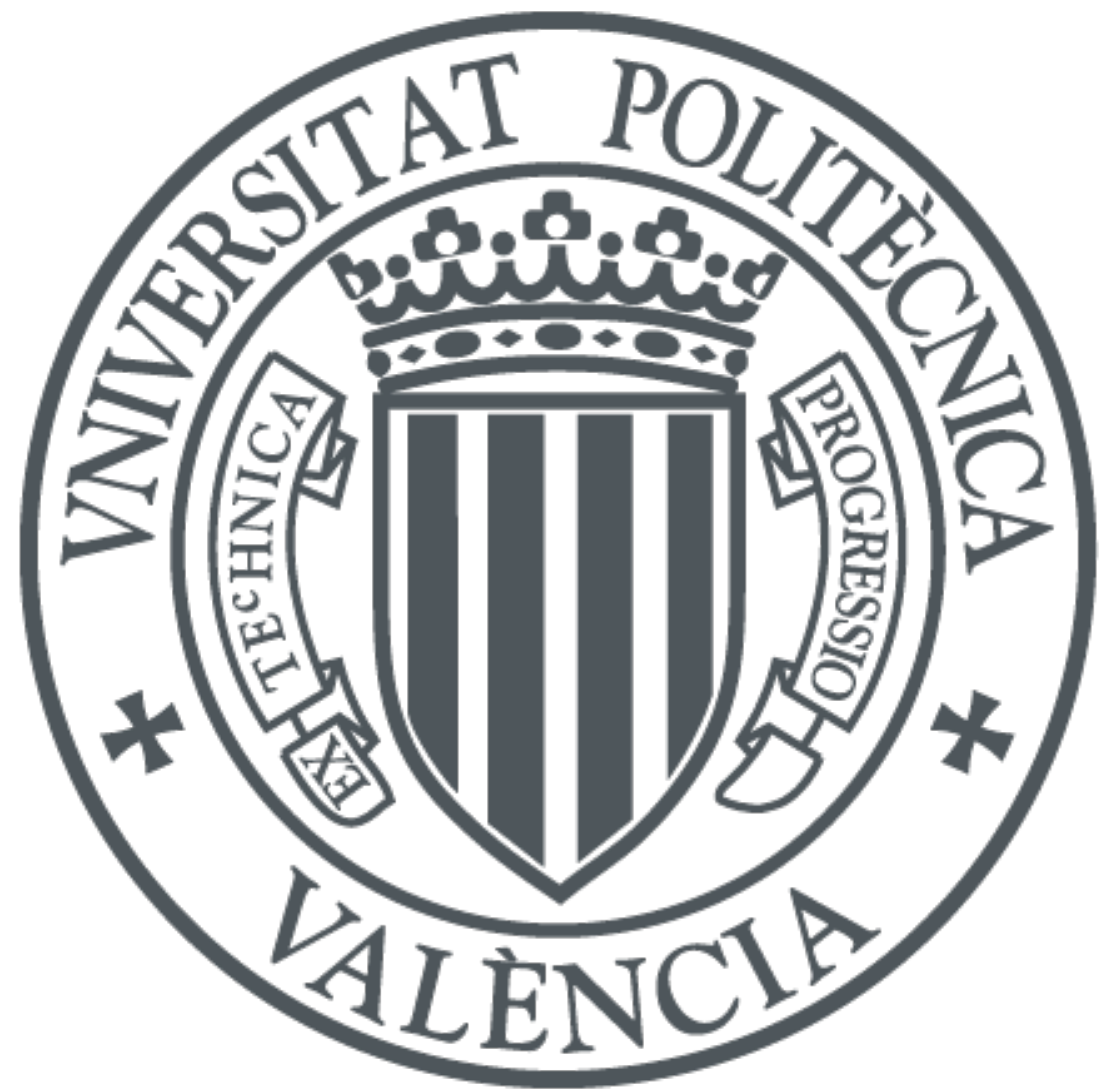

The final publication is available at

http://doi.org/10.1177/0954409717737226

Copyright SAGE Publications

Additional Information 


\section{Modelling train energy consumption in Diesel Multiple Units}

Pablo Salvador Zuriaga ${ }^{1, *}$, Pablo Martínez Fernández ${ }^{1}$, Ignacio Villalba Sanchis ${ }^{1}$, Ricardo Insa Franco ${ }^{1}$

*corresponding author: Pablo Salvador Zuriaga. pabsalzu@upv.es

${ }^{1}$ Institute for Transport and Territory, Polytechnic University of Valencia

Camino de Vera, s/n 46022 Valencia (Spain)

\section{ABSTRACT}

This study presents a train simulation tool for the evaluation of train path and energy consumption. The simulation tool consists of a train dynamic model and an energy consumption model, specifically developed for a Diesel Multiple Unit. The models' performance is tested against a set of measured data including fuel consumption and speed profiles from real operation services. Results yield adjustment errors below $9 \%$ in all simulations, including simplified route profiles. The consideration of wind speed and direction further contributes to improve speed adjustment by $1.5 \%$ in those stretches where such variables taken into account. Hence, it can be used to predict the travel time and the fuel consumption in any potential railway service even at an early stage design.

\section{KEYWORDS}

train energy consumption; train fuel monitoring; diesel multiple unit; energy-driving best practices; energy consumption modelling

\section{INTRODUCTION}

Over the last years, some strategies have been implemented with the aim to reduce energy consumption in railways. The main goals are to be more economically competitive as well as environmentally friendly. Among these strategies, the most relevant ones are the design of railway layouts with energy-efficient criteria, the improvement of rolling stock, the application of energy-saving strategies in railway operations and the smart linkage of energy supply networks ${ }^{1,2}$. 
In the field of driving strategies, it is essential to count with an appropriate energy consumption model. These models may substantially vary depending on the rail system they are applied to. In commuter or suburban trains, with high traffic density and usually electrified networks, train interaction ${ }^{3,4}$, traffic re-scheduling ${ }^{5,6}$, and energy recovery systems ${ }^{7}$ have been investigated. In other applications for electric trains in conventional or high speed lines, energy consumption models may be based on efficient speed profile generators $^{8,9}$. In the case of hybrid diesel trains or locomotives, the most important issue is to account for the possibility of recovering the energy from braking events ${ }^{10,11}$.

For freight trains, authors also focused on driving techniques and minimising energy consumption ${ }^{1,12}$ for which specific train parameters were obtained. Other studies indicate that it is possible to save energy under rigorous restriction of schedule time by keeping train speed uniform ${ }^{13}$, and demonstrate a formal method for optimising traction energy consumption during a single-train journey. In order to appropriately model the driver's behaviour when manipulating the locomotive handles, fuzzy predictive control has been also used $^{14}$. Finally, data mining and driving experience has been applied so as to improve energy efficiency ${ }^{15}$.

The most usual option to model energy consumption is to use a suitable dynamic equation, in which all the coefficients have been adapted to the specific train or railway system. Indeed, there are different driving styles, different types of pre-set speed within Automatic Train Operation (ATO) systems, railway traffic regulations, and influential factors such as the speed profile of a line and the existence of temporary speed limitations. Nevertheless, energy consumption may be modelled by using neural networks as well ${ }^{16,17}$. In this last case, the neural network may implicitly take into account some of these factors.

From the above literature review, one may see that most energy consumption models focus on electric trains. For diesel trains, available models mainly pay attention to conventional loco-hauled trains. Thus, the field of energy consumption of Diesel Multiple Units (DMUs) is not sufficiently covered. Moreover, the effect of the accuracy of the input data and the presence of wind on the results is neither conveniently analysed.

Within this framework, this paper presents an energy consumption model simulator purposely developed for diesel-hydraulic trains, being used in commuter and regional services in non-electrified lines. The model has been validated by means of fuel and train path measurements in two different scenarios with satisfactory results. It further considers the effect of wind in air drag resistance, which is usually disregarded. Additionally, the quality of the data from the track layout is tested for robustness. In this study, the model is designed to be later applied to an off-line driving simulator so that the users may perform different driving strategies and find the most efficient way to drive a train without compromising punctuality. Additionally, the travel time and fuel consumption of any railway line where a DMU similar to the modelled one may run can be easily evaluated as well.

In the text, the underlying equations on which the energy consumption model is based are firstly introduced. Secondly, the model is tested and validated with real fuel consumption measurements. Thirdly, the simulation tool is tested against robustness of the longitudinal profile, calculation step and wind presence. Finally, the most important remarks are highlighted. 


\section{MODEL DESCRIPTION}

The train driving simulator is based on two models. On the one hand, the dynamic model, which yields the movement variables (i.e. position, speed and acceleration) depending on the forces acting on the train at every instant. On the other hand, the fuel consumption model which, depending on the demanded tractive effort, speed and other dynamic variables, yields the throttle position, the engine revolutions and the fuel flow. Both models are solved upon the Finite Differences Method (FDM). This method solves differential equations step by step, assuming constant forces between subsequent steps. All the parameters, tables and values presented have been calibrated and validated by means of a comprehensive monitoring campaign involving fuel measurements in real train services ${ }^{18}$.

These types of FDM models usually operate through two different modes: time step or distance step. The most common way is time step, although in this case, the distance approach has been chosen because the number of calculation steps only depends on the route length and therefore the instant location of singular points, i.e. stations, signals, etc. does not vary with the travel time. Furthermore, layout properties such as maximum speed, gradient or radius are evaluated at the same points, avoiding interpolation.

\subsection{Dynamic model}

The dynamic model relates the tractive or braking effort with the rest of the forces acting on the train, upon Newton's $2^{\text {nd }}$ law in the movement direction. Therefore, at every distance step $j \Delta x$ Eq. (1) must be fulfilled.

(1)

$$
F_{e}=\sum_{k=1}^{n x} m_{k}\left(C_{m g} \ddot{x}+g i_{k}+\frac{8}{R_{k}}\right)+A+B \dot{x}+\frac{C T_{f}}{n x} \sum_{k=1}^{n x}\left(\dot{x}-v_{w} \cos \alpha_{k}\right)^{2}
$$

Equation variables are shown in Table 1 . In this equation, the total train mass has been split into a chain of punctual masses $m_{\mathrm{k}}, k$ ranging from 1 to $n x$, so that $n x$ is the result of dividing the total train length $l_{\mathrm{t}}$ between the distance step $\Delta x$ :

$$
n x=\max \left(1, \operatorname{round}\left(\frac{l_{t}}{\Delta x}\right)\right)
$$

In this way, the train is not considered as a punctual mass, but rather as a set of punctual masses separated a distance $\Delta x$ which cover the total train length. This can be interesting for long trains since some parts may be in a downhill whereas some others may be in a flat stretch or in an uphill. Moreover, each $m_{\mathrm{k}}$ may take different magnitudes, accounting for the respective weights of the different train parts (locomotive, empty wagons, etc.).

In the same way, $i_{\mathrm{k}}, R_{\mathrm{k}}$ and $\alpha_{\mathrm{k}}$ refer to the gradient, curve radius and angle between the layout and the wind for each $m_{\mathrm{k}}$, respectively.

\begin{tabular}{|c|l|}
\hline$m_{\mathrm{k}}$ & value of each single mass $(\mathrm{kg})$ \\
\hline$n x$ & Number of masses the train is split into \\
\hline$l_{\mathrm{t}}$ & Train length $(\mathrm{m})$ \\
\hline
\end{tabular}




\begin{tabular}{|c|l|}
\hline$\Delta x$ & Distance step (m) \\
\hline$i_{\mathrm{k}}$ & Gradient relative to $m_{\mathrm{k}}$ \\
\hline$R_{\mathrm{k}}$ & Curve radius relative to $m_{\mathrm{k}}(\mathrm{m})$ \\
\hline$\alpha_{\mathrm{k}}$ & Angle between the wind direction and the track layout at $m_{\mathrm{k}}$ position \\
\hline$F_{\mathrm{e}}$ & Train tractive/braking effort $(\mathrm{kN})$ \\
\hline$C_{\mathrm{mg}}$ & Rotating mass coefficient \\
\hline$\ddot{x}$ & Longitudinal acceleration $\left(\mathrm{m} / \mathrm{s}^{2}\right)$ \\
\hline$g$ & Gravitational acceleration $\left(\mathrm{m} / \mathrm{s}^{2}\right)$ \\
\hline$\dot{x}$ & Train speed $(\mathrm{m} / \mathrm{s})$ \\
\hline$A$ & Mechanical resistance $(\mathrm{kN})$ \\
\hline$B$ & Air drag resistance, proportional to the speed $(\mathrm{kN} /(\mathrm{m} / \mathrm{s}))$ \\
\hline$C$ & Air drag resistance, proportional to the square of the speed $\left(\mathrm{kN} /(\mathrm{m} / \mathrm{s})^{2}\right)$ \\
\hline$T_{\mathrm{f}}$ & Tunnel factor \\
\hline$v_{\mathrm{w}}$ & Wind speed $(\mathrm{m} / \mathrm{s})$ \\
\hline
\end{tabular}

Table 1 - Significance of variables for Eq. (1).

Since the route is discretised at intervals of $\Delta x$, the energy consumption at every distance step $E_{\mathrm{j}}$ can be obtained in the following way:

$$
E_{j}=F_{e j} \Delta x
$$

The total energy consumption $E_{\mathrm{t}}$ is obtained by adding-up only those intervals in which the energy consumption is positive, i.e.

$$
E_{t}=\left.\sum_{j} E_{j}\right|_{E_{j}>0}
$$

In addition, the time needed to cover each distance step $j \Delta x$ is given by the equations of the uniformly accelerated movement:

$$
\begin{gathered}
\Delta t_{j}=\frac{\dot{x}_{j}-\dot{x}_{j-1}}{\ddot{x}_{j-1}} \\
\Delta t_{j}=\frac{\Delta x}{\dot{x}_{J}}\left(\text { if } \ddot{x}_{j-1}=0\right)
\end{gathered}
$$

(6)

Finally, the speed at the next instant is obtained again by means of the equations of the uniformly accelerated movement:

$$
\dot{x}_{j+1}{ }^{2}=\dot{x}_{j}^{2}+2 \ddot{x}_{j} \Delta x
$$

\subsection{Consumption model}

For this case, a Diesel Multiple Unit (DMU) Series 592.200 has been modelled. This DMU consists of three cars, the extreme ones being motorised, with a total number of four diesel engines, two per car. Each engine moves its nearest bogie by means of a hydrodynamic 
transmission. In these DMUs, the throttle has 6 notches, plus the idle position. In addition, the hydrodynamic transmission has $\mathrm{t}$ wo gears, whose behaviour is featured in terms of engine revolutions, train speed and fuel consumption. Table 2 shows the relations between the throttle position, the engine revolutions and the fuel flow for the first gear.

\begin{tabular}{|r|r|r|}
\hline $\begin{array}{l}\text { Throttle } \\
\text { (position) }\end{array}$ & $\begin{array}{l}\text { Engine } \\
\text { revolutions (rpm) }\end{array}$ & Fuel flow (1/h) \\
\hline 0 (idle) & 750 & 1.33 \\
\hline 1 & 870 & 4.20 \\
\hline 2 & 1130 & 10.0 \\
\hline 3 & 1350 & 18.0 \\
\hline 4 & 1600 & 26.2 \\
\hline 5 & 1850 & 39.7 \\
\hline 6 & 1950 & 60.6 \\
\hline
\end{tabular}

Table 2 - Relation between throttle position, engine revolutions and fuel flow for the first gear

When the train reaches the speed of $94 \mathrm{~km} / \mathrm{h}$, the transmission automatically switches to second gear, and therefore behaves as shown in Table 3. In this table, $v$ stands up for the train speed in $\mathrm{km} / \mathrm{h}$.

\begin{tabular}{|l|l|l|}
\hline $\begin{array}{l}\text { Throttle } \\
\text { (position) }\end{array}$ & $\begin{array}{l}\text { Engine } \\
\text { revolutions (rpm) }\end{array}$ & Fuel flow (l/h) \\
\hline 0 (idle) & 750 & 1.33 \\
\hline 1 & \multirow{4}{*}{$11.7 v+378$} & 10 \\
\hline 2 & & 18 \\
\hline 3 & & 29 \\
\hline 4 & & 35 \\
\hline 5 & & 46 \\
\hline 6 & & $0.3358 v+17.339$ \\
\hline
\end{tabular}

Table 3 - Relation between throttle position, engine revolutions and fuel flow for the second gear

Subsequently, total fuel consumption $V$ is obtained by summation of all the time increments obtained in Eq. (5) and (6) multiplied times the respective fuel flow $Q_{\mathrm{j}}$, i.e.

$$
V=\sum_{j} Q_{j} \Delta t_{j}
$$

The relation between the tractive force from Eq. (1) and the correspondent throttle notch is shown in Fig. 1. In this figure, the traction-speed curves are drawn for each throttle position. The resistance to the movement with null gradient, according to Davis' coefficients $A, B$ and $C$, is shown as well. 


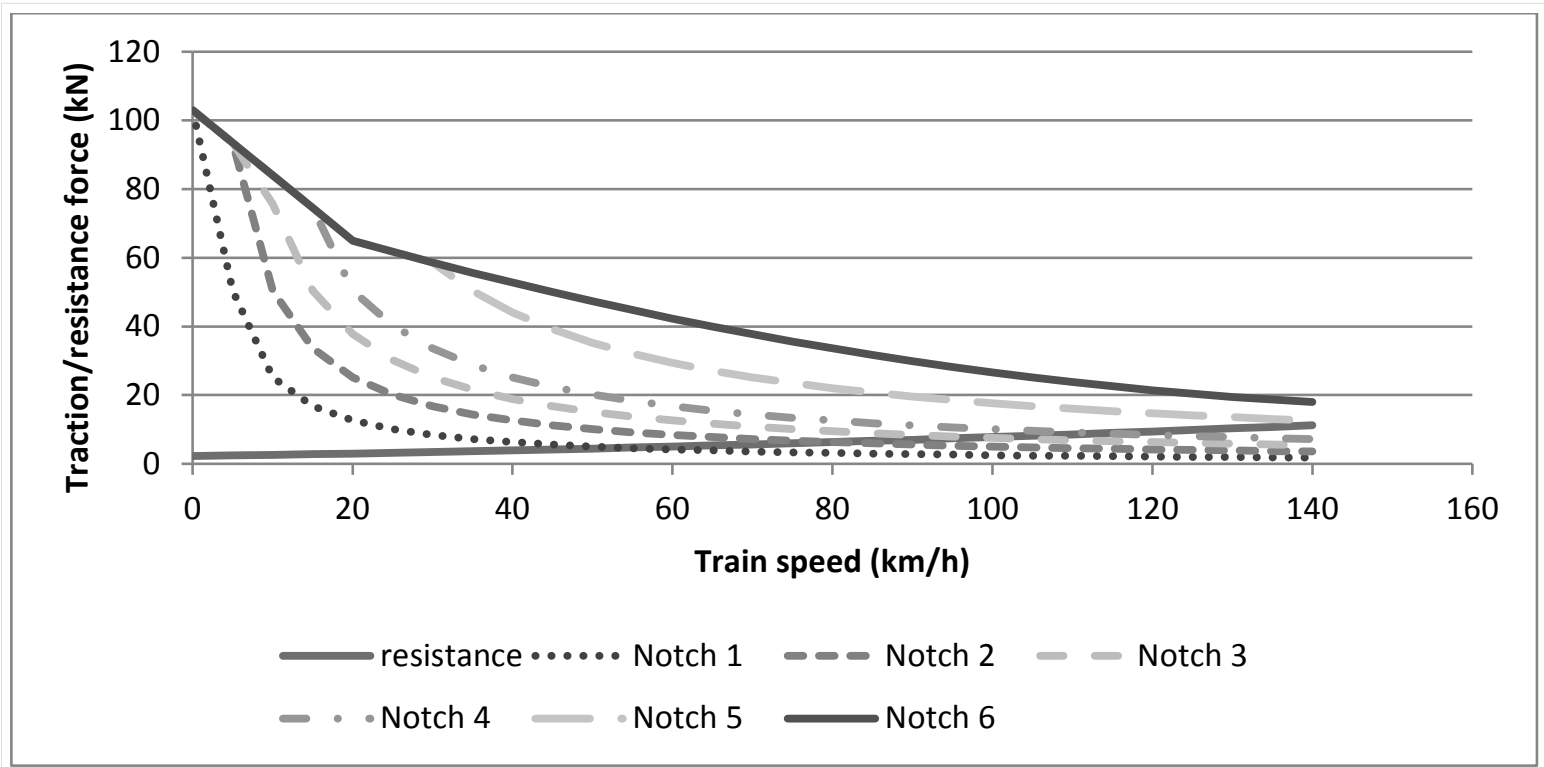

Fig. 1. Traction-speed curves for each throttle position of DMU series 592.200.

The numerical values of the modelled DMU necessary for the simulation are shown in Table 4.

\begin{tabular}{|l|r|}
\hline \multicolumn{1}{|c|}{ Parameter } & \multicolumn{1}{c|}{ Value } \\
\hline$M$ (total mass) & $131 \mathrm{t}$ \\
\hline$I_{\mathrm{t}}$ & $75 \mathrm{~m}$ \\
\hline$C_{\mathrm{mg}}$ & 0.055 \\
\hline$A$ & $2.452 \mathrm{kN}$ \\
\hline$B$ & $0.1164 \mathrm{kN} /(\mathrm{m} / \mathrm{s})$ \\
\hline$C$ & $0.002938 \mathrm{kN} /(\mathrm{m} / \mathrm{s})^{2}$ \\
\hline
\end{tabular}

Table 4. Numerical values of the modelled DMU for the simulation

\section{MODEL TESTING}

The model has been tested in two different routes under different circumstances, both located in the nearby area of Valencia (Spain). The first route is a direct service between Valencia and Xàtiva, which are $55.7 \mathrm{~km}$ away. The second route is a commuter service between Valencia and Utiel, with 11 intermediate stops and a total length of $85.3 \mathrm{~km}$. Tests compare the model results in terms of speed profile and fuel flow by means of the relative Mean Squared Error (rMSE). The formula for the MSE is given by

$$
M S E=\frac{\sum_{n}\left(\hat{y}_{n}-y_{n}\right)^{2}}{N}
$$

where $\hat{y}_{n}$ is the $n$th term of the vector of $N$ predictions and $y_{n}$ is the $n$th term of the vector of $N$ measurements. From this, the rMSE is obtained from dividing the MSE by the variance of the vector of $N$ measurements $\mathbf{Y}$, i.e.

$$
r M S E=\frac{M S E}{\operatorname{var}(\mathrm{Y})}
$$

Similarly to ${ }^{19}, 0 \%<$ rMSE $<100 \%$ measures the proportion of the variance not explained by the model. Hence, the lower the rMSE, the better, the model properly represents the real 
phenomenon. In global terms, relative errors for the total travel time and fuel consumption are given as well. For all simulations, excluding 3.4, a distance step of $\Delta x=0.1 \mathrm{~km}$ has been chosen.

\subsection{Route Valencia - Xàtiva}

For this simulation, the throttle positions at every interval have been adopted so that the modelled speed profile approaches the registered speed profile as much as possible. Afterwards the fuel consumption is obtained for this set of throttle positions. Under these conditions, Fig. 2 shows the measured and modelled speed profiles. In this figure, a good agreement between both speed profiles is observed. Only in the stretch between mileposts 20 and 30 there are slight differences. It is worth noting that the longitudinal profile of this stretch is mostly flat. Only the last 16 kilometres have a mild ramp of $5 \mathrm{~mm} / \mathrm{m}$.

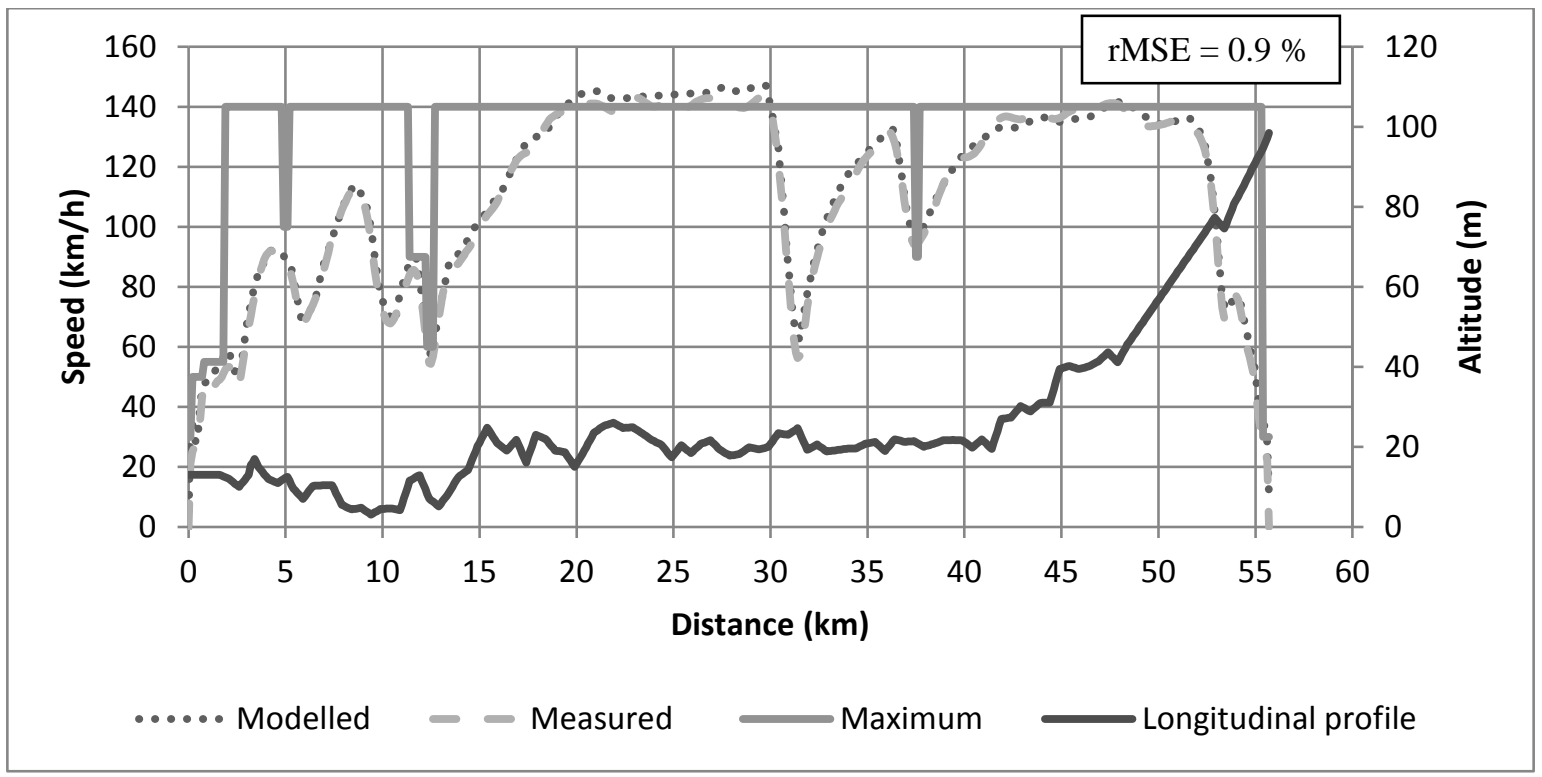

Fig. 2. Speed and longitudinal profiles for the route between Valencia and Xàtiva

Fig. 3 shows both the modelled and the measured instantaneous fuel consumption. Again, both curves show a good agreement, despite a dip in the modelled fuel consumption in milepost $13 \mathrm{~km}$. In this place, a punctual difference between the modelled and the actual resistance causes the tractive power to be lower than in reality. The results of the simulation are shown in Table 5. 


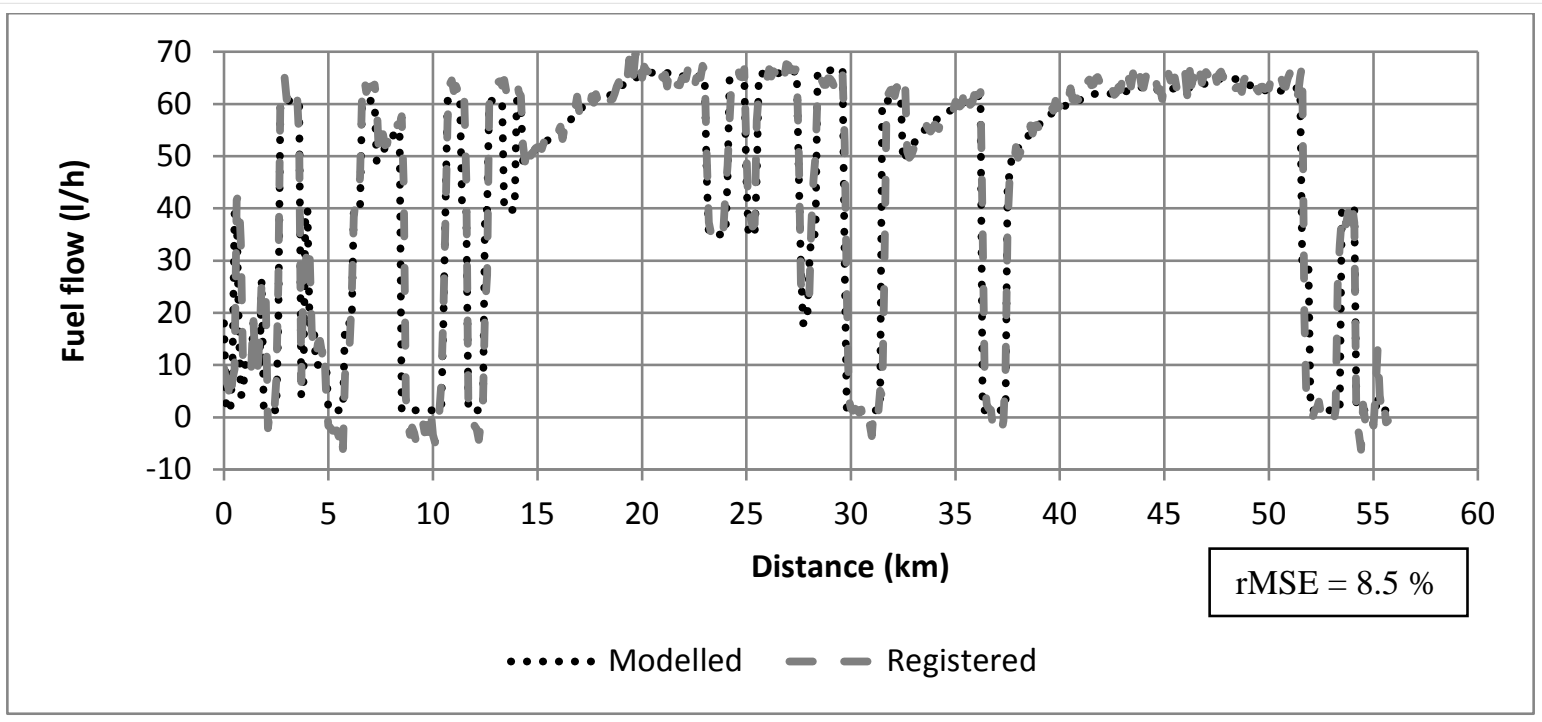

Fig. 3. Modelled and registered fuel flows for the route between Valencia and Xàtiva

The rMSE for both the speed and the fuel flow remains below the threshold of $20 \%$, which indicates a good adjustment. In the case of the speed, it is near zero since the modelled speed profile has been forced to follow the measured one. Small variations are due to the fixed throttle notch positions, which can only apply discretised tractive effort; and the distance step, which introduces some inaccuracy. For the fuel consumption, slight differences between the predicted and the actual notch positions cause some deviations in fuel flow which yield an error of $4.1 \%$ in the overall fuel consumption.

\subsection{Route Valencia - Utiel}

The train service between Valencia and Utiel is a commuter service of $85.3 \mathrm{~km}$ long and 11 intermediate stops. In this case, the throttle positions have been obtained taking as an input the measured fuel flow, for which a specific algorithm was developed. In this case, during data monitoring, there was an eastward wind about $30 \mathrm{~km} / \mathrm{h}$ blowing in the opposite direction of the train route between mileposts 5 and $30 \mathrm{~km}$. The test measurements for this route yield a travel time of 1 hour, 39 minutes and 12 seconds and a total fuel consumption of 190.5 litres. Fig. 4 shows the measured and the actual speed profiles, together with the longitudinal profile for this route. Again, a good concordance between both speed profiles is observed.

Only small discrepancies are found at mileposts 60, 63 and in the 80-85 km interval. In this case, the route is mostly uphill until milepost $55 \mathrm{~km}$. After this, a succession of mild up and down grades follows. 


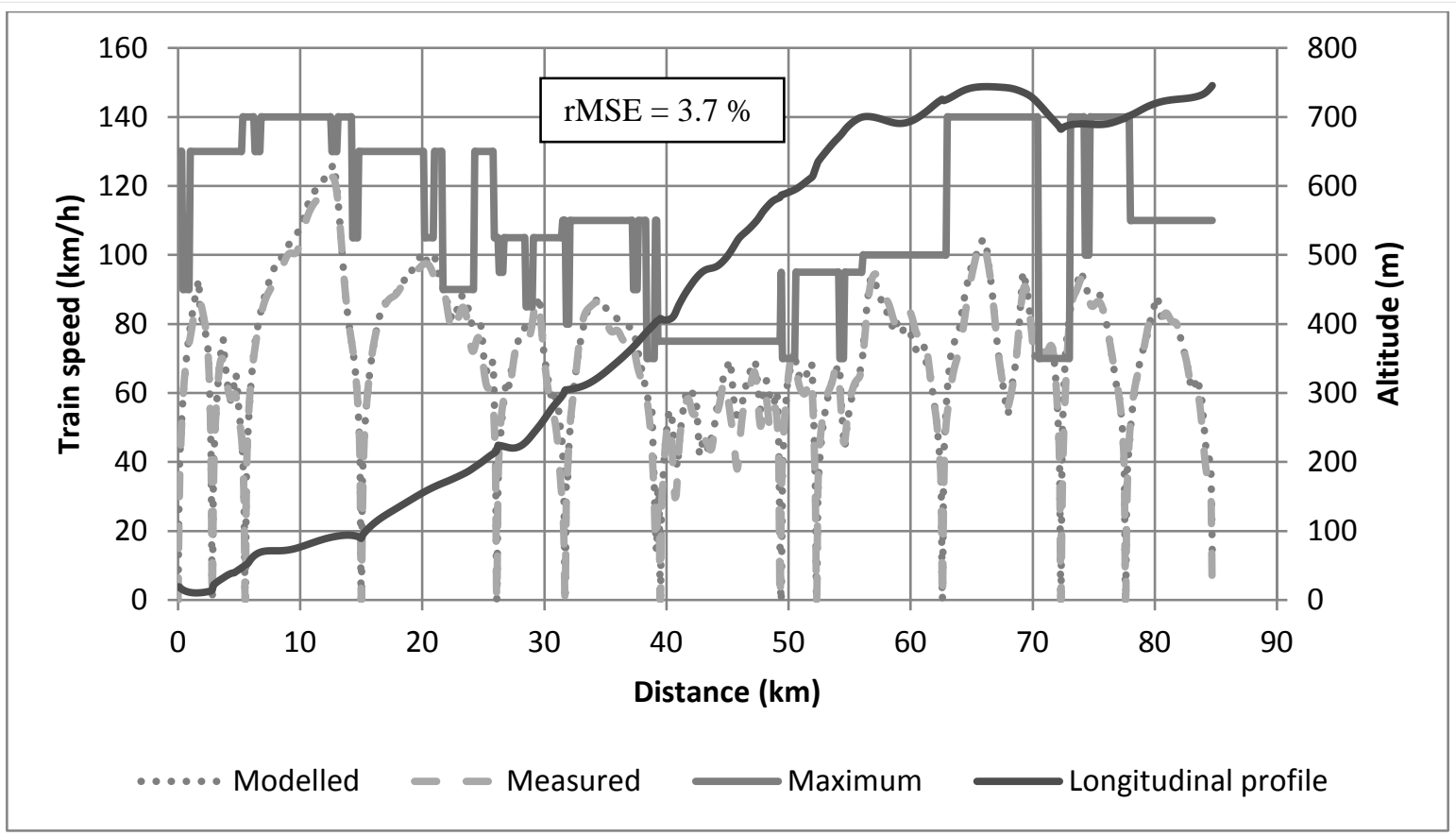

Fig. 4. Speed and longitudinal profiles for the route between Valencia and Utiel

Fig. 5 shows the predicted and actual fuel flow series for this route. Although the overall concordance is good, there are some dips in the predicted fuel flow at mileposts 18, 30 and $60 \mathrm{~km}$, which do not appear in the measurements. The difference at milepost $18 \mathrm{~km}$ is caused by the switch of gear in the hydrodynamic transmission. In all these cases, the speed is around the value of $94 \mathrm{~km} / \mathrm{h}$ in which the train switches from first to second gear and viceversa. Due to small differences, the exact point of gear switching may differ, leading to punctual differences in the fuel estimation. The mismatches at milepost 30 and $60 \mathrm{~km}$ are caused by the fact of suddenly cutting traction power and the discretisation of the registered flow time series.

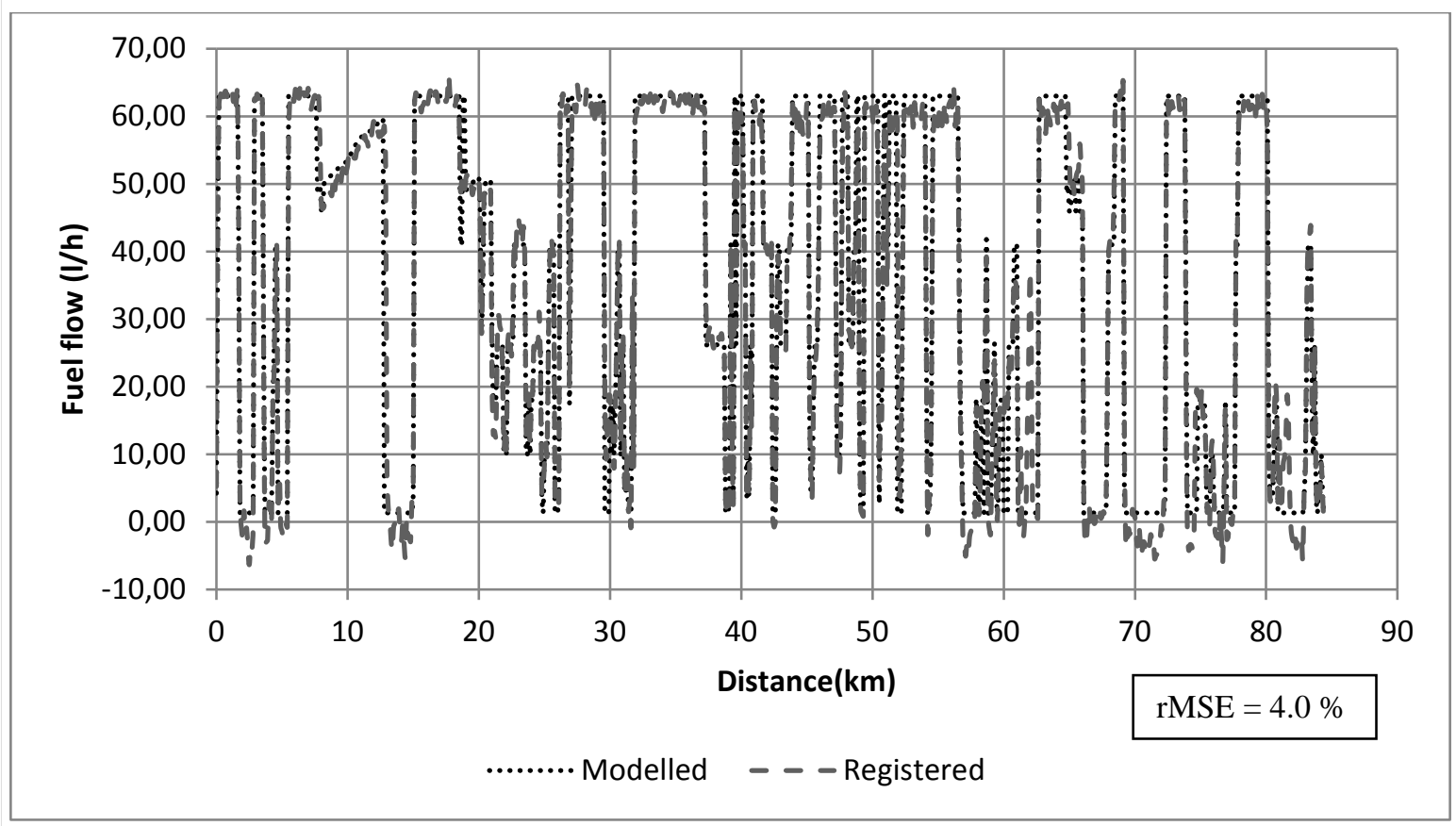

Fig. 5. Modelled and registered fuel flows for the route between Valencia and Utiel 
The performance indicators are shown in Table 5. Again, both rMSE are far below 20\%, so the model appropriately simulates the train journey. In this case, since the throttle notch positions have been obtained from the fuel flow measurements, the rMSE for the fuel consumption has improved whereas the rMSE for the speed has slightly worsened respect to the Valencia-Xàtiva journey. In overall terms, the relative error has also increased slightly, being in this case $0.92 \%$. Nevertheless, the relative error for total fuel consumption has considerably been reduced down to $0.34 \%$.

In spite of the accuracy of fuel flow predictions, there are two evidences the model does not take into account. The first one is some flow fluctuations that appear between mileposts 40 and 65. In this interval, the measured flow is perceptibly lower than the predicted one. These variations are mainly due to train intern efficiency variations, which depend on the working temperature, cooling capability, etc. and are difficult to implement in the model. The second one is a reflux produced in the engines when the driver cuts off traction power which yields negative flows (i.e. fuel return to the tank). This can be observed around mileposts 3, 57, 71 and $83 \mathrm{~km}$. Since a direct cause has not been found, the model considers this fuel detriment in the average fuel consumption during idling.

\subsection{Effect of the quality of the longitudinal profile data}

For simulations shown in previous sections, route vertical profile data has been obtained by means of a high accuracy GPS. This data has been further processed with the aid of 3D modelled land representations so as to achieve realistic gradient information at every evaluated point of the route. Nevertheless, it is often very difficult to have access to reliable data from the track layout, especially for new lines which are at an early design stage. In order to take into account this situation, the proposed model is tested for robustness, for which the vertical alignment is replaced by a more simple vertical profile. This vertical profile only considers the altitude of some relevant points, such as stations or significant gradient changes (from positive to negative and vice-versa). Gradient between two adjacent points is thus considered constant. This is likely the type of information the railway administrator provides to private operators so as to allow them to have a basic knowledge of the route they are operating.

Under these conditions, Fig. 6 shows the simplified vertical profile for the Valencia-Utiel route, together with modelled, measured and maximum speed. Its respective numerical results are shown in Table 5. In this case, there are bigger discrepancies between modelled and measured speed profiles, particularly after milepost $55 \mathrm{~km}$ as the sinusoidal part of the layout begins. As a matter of fact, the rMSE for the speed increases from 3.7\% to $7.4 \%$. In this case, the relative error for total travel time diminishes, but this cannot be considered as a significant result since the cause is that some parts where the modelled speed is lower than the measured are cancelled with some others where the former is higher than the latter. Variations in fuel consumption are very small since the throttle positions from previous simulation are kept the same. These are produced by different instants the transmission switches gears. 


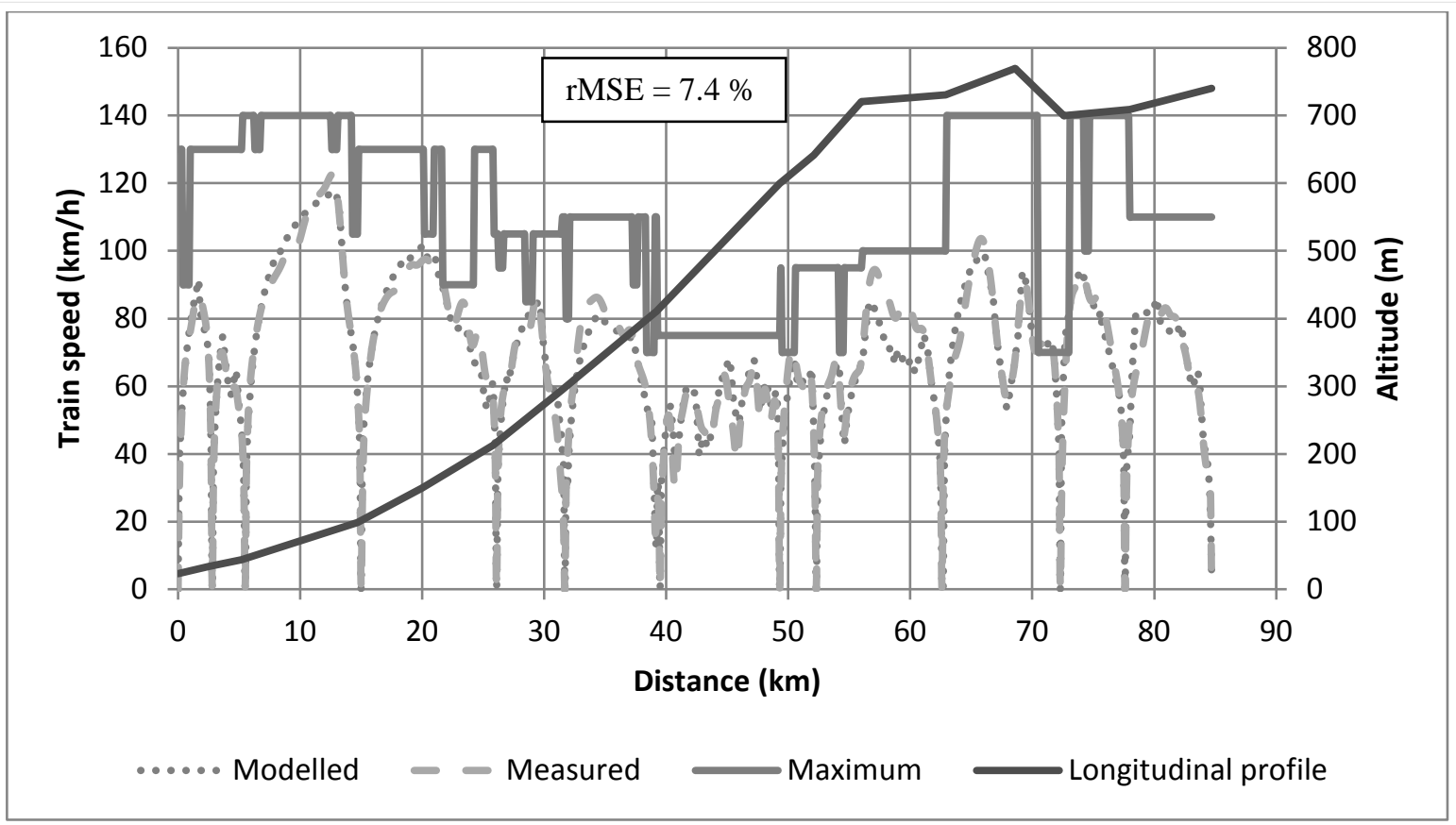

Fig. 6. Speed profile equivalent for Fig. 4 with a simplified longitudinal profile.

\subsection{Effect of distance step}

All the previous simulations have been performed using a distance step of $100 \mathrm{~m}$, since it yields a good compromise between results accuracy and number of calculation steps so as to cover a certain distance. In order to test this, the same simulation carried out in section 3.2 is now performed using a distance step of $20 \mathrm{~m}$. The model performance parameters of Table 5 show that the rMSE for the speed has slightly decreased from 3.7\% to 3.5\%, whereas the rMSE for the fuel flow has moved from $4.0 \%$ to $3.3 \%$. In overall terms, the relative error for total travel time is $0.07 \%$ and for total fuel consumption $0.37 \%$. Although all the variables have improved, particularly the total travel time and fuel consumption, this improvement is not considered worthy if compared to the increment of calculus steps, which have risen from 850 to 4250 .

\begin{tabular}{|c|c|c|c|c|}
\hline & \multicolumn{3}{|c|}{$\Delta x=100 \mathrm{~m}$} & $\Delta x=20 \mathrm{~m}$ \\
\hline Indicator & $\begin{array}{l}\text { Valencia- } \\
\text { Xàtiva }\end{array}$ & $\begin{array}{l}\text { Valencia- } \\
\text { Utiel }\end{array}$ & $\begin{array}{l}\text { Valencia- } \\
\text { Utiel } \\
\text { simplified } \\
\text { profile }\end{array}$ & $\begin{array}{l}\text { Valencia- } \\
\text { Utiel }\end{array}$ \\
\hline rMSE speed & $0.90 \%$ & $3.7 \%$ & $7.4 \%$ & $3.5 \%$ \\
\hline rMSE fuel & $8.5 \%$ & $4.0 \%$ & $6.6 \%$ & $3.3 \%$ \\
\hline relative error for travel time & $0.43 \%$ & $0.92 \%$ & $0.66 \%$ & $0.07 \%$ \\
\hline relative error for fuel consumption & $4.1 \%$ & $0.34 \%$ & $0.50 \%$ & $0.37 \%$ \\
\hline
\end{tabular}

Table 5. Model performance parameters for the all the analysed routes and their variations. 


\subsection{Effect of the wind}

As commented before, whereas in the simulation for the Valencia-Xàtiva route no wind was considered, for the route between Valencia and Utiel, a wind of $30 \mathrm{~km} / \mathrm{h}$ blowing in the opposite direction of the train's movement between mileposts 5 and $30 \mathrm{~km}$ was detected. In order to further analyse the effect of wind in the total resistance and hence the speed profile, a stretch from the Valencia-Utiel route, between mileposts 5.5 and $26.1 \mathrm{~km}$, has been selected, coinciding with two intermediate stops. This stretch corresponds to a relatively flat zone near Valencia where winds blowing up to $60 \mathrm{~km} / \mathrm{h}$ eastwards and up to $30 \mathrm{~km} / \mathrm{h}$ westwards are likely to occur.

Fig. 7 shows the variation of speed profiles with the wind, assuming in all cases the same set of throttle positions (i.e. engine output power) at every point of the stretch. Differences about $20 \mathrm{~km} / \mathrm{h}$ arise between the most favourable and the most adverse scenarios. Furthermore, a wind speed of only $30 \mathrm{~km} / \mathrm{h}$ may produce variations of $5 \mathrm{~km} / \mathrm{h}$ in the train speed profile. This means that sometimes, a fine tuning of the simulator variables is worthless unless a good knowledge about the wind map of the zone is provided. This is of relevance when applying partial tractive effort, as it can be perceived from milepost $22 \mathrm{~km}$ onwards. If compared to the measured train speed, considering a wind speed of $30 \mathrm{~km} / \mathrm{h}$ contributes to lower the speed rMSE from $2.3 \%$ to $0.8 \%$ with respect to not taking it into account for this analysed stretch.

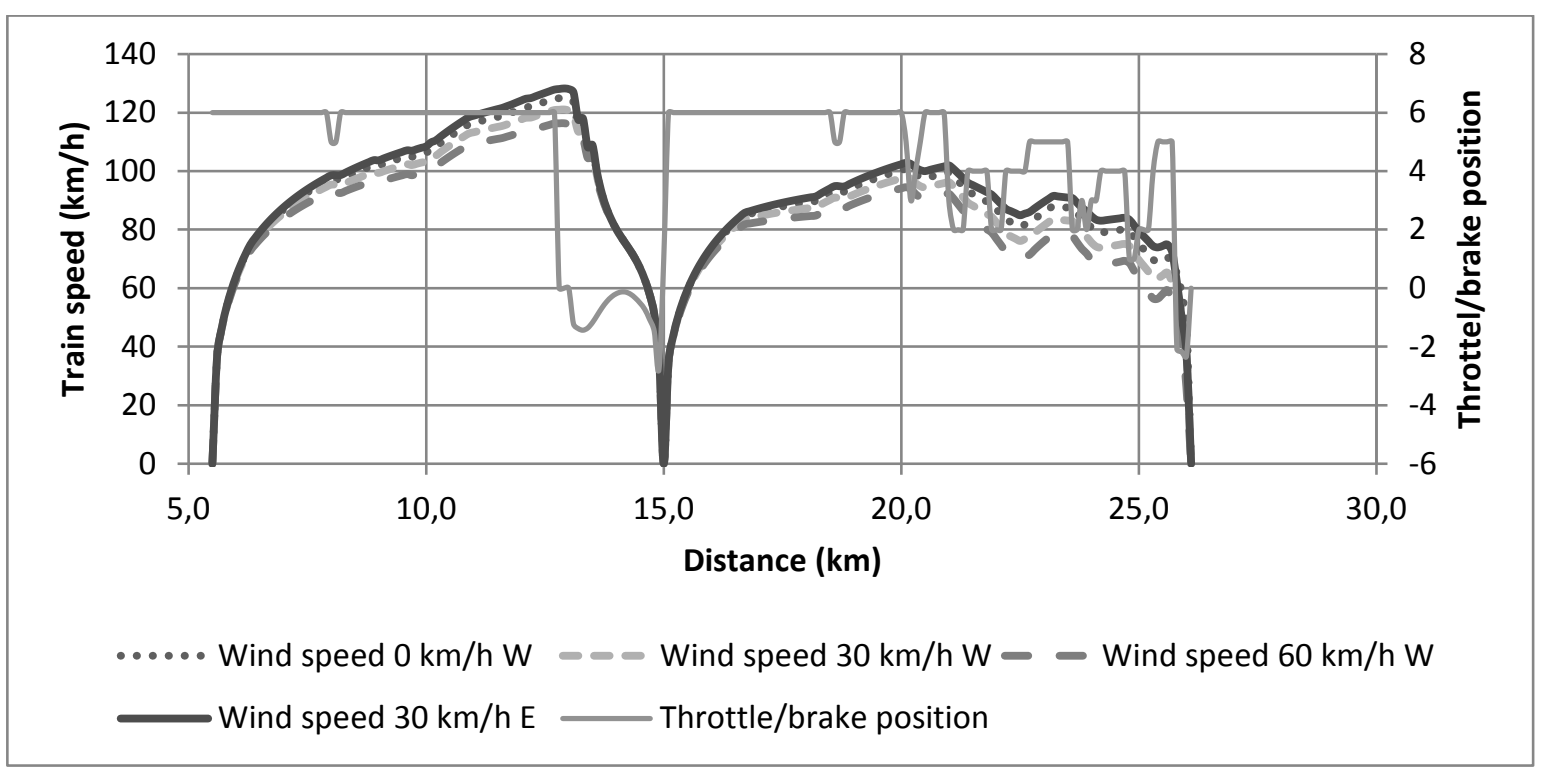

Fig. 7. Effect of wind in the speed profile.

\section{CONCLUSIONS}

A train simulation tool for hydrodynamic DMUs has been presented in this study. This tool is based on a dynamic model and a fuel consumption model. Both of them were previously calibrated and validated by means of an extensive fuel monitoring campaign on real train services. The dynamic model considers the train as a set of punctual masses, the different acting forces being applied over each of them. The model considers specific curvature resistance at every point of the layout, as well as wind speed and direction. 
Simulations have been performed in two different routes, and the effect of varying the longitudinal profile and the distance step for calculations has been analysed. All simulations have yielded error adjustments under $9 \%$, below the $20 \%$ threshold that stablishes a good adjustment between predicted and measured data. This includes the scenario of simplified longitudinal profile data, which only considers the altitudes at significant points such as stations and gradient changes and assumes constant gradients between those points. In addition, the consideration of wind contributes to improve the speed profile adjustment lowering the rMSE from $2.3 \%$ to $0.8 \%$. The wind analysis further shows that a wind of 30 $\mathrm{km} / \mathrm{h}$ blowing in the opposite direction of the train's movement may produce variations about $+/-5 \mathrm{~km} / \mathrm{h}$ in the speed profile.

Once the model has been validated, the results can be applied to any railway route to evaluate both the travel time and the fuel consumption produced by a DMU similar to the modelled one. This may be of interest for improving energy-saving driving styles and for the estimation of operational costs in new lines or new offered services.

\section{ACKNOLEDGEMENTS}

The authors would like to thank Renfe Operadora for its help during the train tests. Project Funded by the Spanish Ministry of Economy and Competitiveness, Ref. TRA 2011-26602.

\section{REFERENCES}

1. Lukaszewicz P. Driving techniques and strategies for freight trains. Computer in Railways VII 2000; 1065-1073.

2. $\quad$ García A. High speed, energy consumption and emissions. UIC 2010; 1-52.

3. Bocharnikov YV, Tobias AM, Roberts C, et al. Optimal driving strategy for traction energy saving on DC suburban railways. IET Electr Power Appl 2007; 1: 675.

4. González-Gil A, Palacin R, Batty P, et al. A systems approach to reduce urban rail energy consumption. Energy Convers Manag 2014; 80: 509-524.

5. Haramina H, Haramina H, Mandić M, et al. New method for energy-efficient train operation on commuter rail networks. Teh Vjesn 2012; 19: 801-806.

6. Carvajal-Carreño W, Cucala AP, Fernández-Cardador A. Optimal design of energyefficient ATO CBTC driving for metro lines based on NSGA-II with fuzzy parameters. Eng Appl Artif Intell 2014; 36: 164-177.

7. De Martinis V, Gallo M. SIDT Scientific Seminar 2012 Models and methods to optimise train speed profiles with and without energy recovery systems: a suburban test case. Procedia -Social Behav Sci 2013; 87: 222-233.

8. Ogawa T, Manabe S, Imamura Y, et al. Development of a train running energy simulator for commercial train running. In: Electrical Systems for Aircraft, Railway and Ship Propulsion, ESARS. 2015. Epub ahead of print 2015. DOI: 10.1109/ESARS.2015.7101434.

9. Sicre C, Cucala AP, Fernández-Cardador A. Real time regulation of efficient driving of high speed trains based on a genetic algorithm and a fuzzy model of manual driving.

Eng Appl Artif Intell. Epub ahead of print 2014. DOI: 10.1016/j.engappai.2013.07.015.

10. Read MG, Griffiths C, Smith RA. The effect of driving strategy on hybrid regional diesel trains. Proc Inst Mech Eng Part F J Rail Rapid Transit 2011; 225: 236-244. 
11. Sun Y, Cole C, Spiryagin M, et al. Longitudinal heavy haul train simulations and energy analysis for typical Australian track routes. Proc Inst Mech Eng Part F J Rail Rapid Transit 2014; 228: 355-366.

12. Lukaszewicz P. Running resistance and energy consumption of ore trains in Sweden. J Rail Rapid Transit 2009; 223: 189-197.

13. Bai Y, Mao B, Zhou F, et al. Energy-Efficient Driving Strategy for Freight Trains Based on Power Consumption Analysis. J Transp Syst Eng Inf Technol 2009; 9: 4350.

14. Bai Y, Ho TK, Mao B, et al. Energy-efficient locomotive operation for chinese mainline railways by fuzzy predictive control. IEEE Trans Intell Transp Syst. Epub ahead of print 2014. DOI: 10.1109/TITS.2013.2292712.

15. Zhang C-YY, Chen D, Yin J, et al. Data-driven train operation models based on data mining and driving experience for the diesel-electric locomotive. Adv Eng Informatics 2016; 30: 553-563.

16. Fernández PM, Román CG, Franco RI. Modelling Electric Trains Energy Consumption Using Neural Networks. Transp Res Procedia 2016; 18: 59-65.

17. Pineda-Jaramillo JD, Insa R, Martínez P. Modeling the energy consumption of trains by applying neural networks. Proc Inst Mech Eng Part F J Rail Rapid Transit 2017; 95440971769452.

18. Salvador Zuriaga P, Insa Franco R, Villalba Sanchis I, et al. Fuel Measurements in Diesel Multiple Units for Energy Management Purposes. In: Pombo J (ed) 2nd International Conference on Railway Technology: Research, Development and Maintenance (RAILWAYS 2014). Ajaccio (Corsica, France): Civil-Comp Press, Stirlingshire, Scotland., 2014, pp. 1-11.

19. Molines J, Medina JR. Explicit Wave-Overtopping Formula for Mound Breakwaters with Crown Walls Using CLASH Neural Network-Derived Data. J Waterw Port, Coastal, Ocean Eng 2016; 142: 4015024. 